\title{
Revisiting the Explicit Learning of Vocabulary of Chinese EFL Learners
}

\author{
Chen Wang ${ }^{1 \& 2}$ \& Jingjing Yang ${ }^{1}$ \\ ${ }^{1}$ Guangdong University of Foreign Languages, China \\ ${ }^{2}$ HongKong Polytechnic University, Hong Kong \\ Correspondence: Chen Wang, Guangdong University of Foreign Languages \& HongKong Polytechnic \\ University
}

Received: November 14, 2019

Accepted: January 12, 2020

Online Published: January 17, 2020

doi: $10.5539 /$ elt.v13n2p 86

URL: https://doi.org/10.5539/elt.v13n2p86

\begin{abstract}
This study intends to find out how the retention of new vocabulary items could be affected by the item type (collocations versus single words), association strength between collocates and the collocate-node relationship. 101 Chinese EFL learners encountered the new items in paired-associate format. Participants were assigned to three groups: learning two types of collocations with high association strength, learning two types of collocations with low association strength, and learning new items in single words. The results show that learning new items in collocations yielded better retention of receptive and productive knowledge of meaning than in single words. Collocations with greater association strength also led to better retention of meaning. Different item types and associate strength has little effect on the retention of form.
\end{abstract}

Keywords: collocations, single words, associate strength, collocate-node relationships, foreign language learning

\section{Introduction}

The learning of collocations has been at the center of the studies into vocabulary learning and teaching of second language learners in recent years. The studies into learner writing have provided repeated evidence of the difficulties that learners have encountered in collocational learning and usage (e.g. Foster, 2001; Hsu \& Chiu, 2008). Schmitt commented that "this suggests that the difficulty learners have is not only that of learning which words go together but also learning how to employ the chunks they know" (p. 144). This observation has justified the growing body of research into the incidental and intentional learning of collocations from different levels of L2 learners. This study tends to look into different potential intrinsic and extrinsic factors that might influence the learning of collocations of language learners, and explore the effect of these factors on the learning of collocations and compare the learning effect with single words.

\subsection{Definition of Collocations in L2}

There are mainly two approaches to defining collocations, i.e., the phraseological approach and frequency-based approach. The advantage of using frequency-based approach is that it provides a quick and objective judgment on the acceptance of collocations. Also, it provides a fast identification of proper collocates for the node words. Since the present study intends to examine the effect of association strength on collocational learning, we would adopt the frequency-based approach in defining collocations. In the present study, the collocations are viewed as "word combinations within a limited span that co-occur more frequency than chance would predict". As Wouden (1997) addressed that adopting the frequency-based collocations has the potential to include idioms, since it does not take the semantic properties of the collocations into accounts, such as congruency of the L1 and L2 collocations (Wolter \& Gyllstad, 2013) and semantic transparency of meaning of L2 collocations (Gyllastad \& Wolter, 2016). However, the target node words of the present study are infrequent words which have a low potential to be used as idioms. The study includes highly transparent collocations such as roam streets and bestselling memoir and collocations with words used in metaphorical sense like unleash in unleash creativity and erode in eroding confidence. The inclusive approach of covering collocations with a degree of transparency would increase the ecological value than a tightly controlled approach which only includes collocations as free combinations or restricted collocations. 


\subsection{Collocations and Single Words in New Item Learning}

The recent second language research has been interested in comparing the learning efficiency of collocations and single words in new item learning. However, till now, there is conflicting evidence as to the teaching and learning of new words in collocations and single words (Kasahara, 2011; Laufer \& Girsai, 2008; Pellicer-Sanchez, 2015; Peters, 2012; Peters, 2014).

These studies have shown a diverse picture of the learning gain of collocations and single words in new item learning. There are several key issues in the methodology in the abovementioned studies that should be viewed with caution. The first issue is on the types of collocations and single words chosen for the study. Most of the studies mentioned above used different sets of node words for single words and collocations. The different node words for collocations and single words might confound the reliability in the comparison of learning gains. In Laufer and Girsai (2008), the frequency levels of single words and collocates in the collocations are quite different. Six out of ten single words were from the 7000 to the 10,000 levels in the BNC word list, i.e., candid, distractor, glean, laudable, opulent and gregarious. Comparatively, only two collocates in the ten collocations were from the 4000 and 5000 word level (reclaim, ambition) and the remaining ones were mostly from the 1000 word level (present a problem, hold a vote, place orders). The pronounced differences between the node words in the collocations and single words made it hard to conclude whether the results of the study could be attributed to the innate quality of collocations or just that the collocations consisting of words that were easier to learn. The second issue is the type of test used for the studies. Kasahara (2011) implemented one type of post-test, i.e., the receptive test of meaning, while, Laufer and Girsai (2008) included two tests of receptive and productive test of meaning. Peters (2014) implemented one test of the productive knowledge of form of the target items. It is interesting that the test tapping into the receptive and productive knowledge of meaning of target items showed that the knowledge of single words lagged behind that of the collocations. Whereas, the studies that implemented the test on the form of the target items showed the opposite results.

\subsection{Factors in Collocational Learning}

Mutual information score (MI) is a statistical measurement of association strength. It could reveal whether the collocates possess high coherence to each other and a high probability of co-occurrence in the corpus or just occurring randomly together. A high mutual information score would indicate that there is strong association between collocates, whereas a low score would imply that the collocates appear together by chance. To verify the psycholinguistic validity of mutual information, Ellis, Simpson-Vlach and Maynard (2008) conducted three experiments to compare the behavior of native speakers and advanced second language learners. The results showed that mutual information is the major determiner of the performance of native speakers in the three experiments. However, L2 learners were not sensitive to the MI scores. Literature in second language research has somewhat revealed findings that are in line with Ellis, Simpson-Vlach and Maynard (2008) with learners from a wider range of L1 backgrounds and proficiency levels to show that learners generally lack the awareness of mutual information between collocates (Fernadez \& Schmitt, 2015). Durrant (2014) carried out a meta-analysis study to explore the relation between collocations knowledge and frequency of collocations in corpora based on the findings of 19 different studies. He concluded that L2 learners' lack of awareness of mutual information between the collocates was a general thing.

Recent experimental studies have used association strength to select target collocations for teaching to ensure that the collocates are strongly associated with each other (e.g., Eyckmans, Boers \& Lindstromberg, 2016; Szudaski \& Carter, 2014). Szudaski and Carter (2014) selected collocations with mutual information score (as a measure of association strength) higher than 3 as the indicator that the collocates tend to co-occur and show collocational pattern. Eyckmans, Boers \& Lindstromberg (2016) also provided mutual information score of the target collocations as a verification of the collocations. They have noted in their study that there had been no existing studies on the effectiveness of mutual information score on the retention of the collocations. To the best of my knowledge, this observation still holds true now.

\subsection{Collocate-node Relationship and Collocational Learning}

Verb-noun collocations and adjective-noun collocations constitute the majority types of collocations in language. Peters (2015) conducted an experimental study into the effect of collocate-node relationship on retention of collocations. 43 Dutch EFL learners of English were asked to learn 18 collocations in word list. The results showed that collocate-node relationship affected the learning of target items. The participants consistently produced more correct answers of adjective-noun collocations, followed by verb-noun collocations and phrasal verb collocations in all three types of posttests.

There are several issues in the methods of Peters (2015) that could be modified to examine the collocate-node 
relationship. The first issue lies in the exercises in the treatment that may undermine the learning of verb-noun collocations. For example, in the fill-in-the-gap exercises, participants were required to fill in the correct forms of the verb-noun collocations which included different inflectional variations. The second issue lies in the need of delayed posttest to examine the effect of learning over a longer period. The implementation of delayed posttest resembles the real learning scenarios that could reflect the attrition of knowledge over a period and inform the researchers on the lasting effects of the learning, which coincides with the goal of learning, i.e., to achieve long-term memory.

Based on the observation of the previous studies, the present study seeks to address the following research question:

1. Are there different learning gains for collocations and single words in explicit teaching?

2. To what extent does the association strength between collocations influence the learning gains in explicit teaching?

3. In what ways does the collocate-node relationship influence the learning of collocations in explicit teaching?

\section{Methodology}

\subsection{Participants}

The participants were 101 English major first-year undergraduate students from three parallel classes in a Chinese university. The three parallel classes were randomly assigned to three experimental groups, who received instruction on collocations and single words. The demographic information of the participants is shown in the Table 1. To examine the proficiency level of the three groups, the vocabulary level test (Schmitt \& Schmitt, 2001) was used. The result of one-way ANOVA showed that the proficiency level of the three groups does not have a significant difference $(F(1,99)=2.334, p=.103)$.

Table 1. Demographic information of participants

\begin{tabular}{ccccc}
\hline & no. of participants & gender(F/M) & average age & English learning (year) \\
\hline Experiment group 1 & 33 & $29 / 4$ & 18 & 8 \\
Experiment group 2 & 35 & $33 / 2$ & 18 & 8 \\
Control group & 33 & $32 / 1$ & 18 & 8 \\
\hline
\end{tabular}

\subsection{Target Items}

There were several steps involved in the selection of target items. The first step was to choose the pool of potential target items. To increase the ecological value of the study, the potential test items were selected from the students' textbooks of intensive reading class and required reading materials of the writing class. To explore the differentiations in the learning gain of collocations with high MI score and low MI score, the present study used the online corpus (corpus.byu.edu) to create the collocates. Table 2 presents the classification of mutual information score used in the present study.

Table 2. Threshold of the Association Strength of Collocations

\section{Categorization of collocations \\ Collocational: low \\ Collocational: medium \\ Collocational: high}

$$
\begin{gathered}
\text { MI score } \\
\geq 3 \text { and }<4 \\
\geq 4 \text { and }<5 \\
\geq 5
\end{gathered}
$$

A pilot test was performed to test any prior knowledge on the chosen items. The pilot test was conducted on two parallel classes of sixty-eight students. Four weeks before the treatment, the pilot test was conducted in the pen-and-paper format on receptive knowledge test where the English word was provided and the students were asked to write down the Chinese meaning of the words. If the correct translation of an English word was given by any student in the class, it was removed from the list.

The present study included 20 collocations and 20 single words (see Appendix). The results of the independent sample t-test show that the MI score of the 20 high MI collocations is significantly higher than that of the 20 low MI collocations $(t=11.939, p=.000)$. The criteria of classifying High and Low MI score is based on the finding of a previous study done by the author on a group of learners with similar backgrounds (Wang, 2019). Beside the target items, four filler items were included in the study: nurture, inhale, smear and ravine. These four filler items included two verbs and two nouns. The selection of filler items and the creation of collocates were based 
on the similar criteria as the target items. The filler items were presented as the first and the last items as the primacy and recency buffers in the learning materials. However, they were not included in the data analysis (Nakata \& Webb, 2015).

\subsection{Dependent Measures}

The present study used three types of tests to examine the learning gains of the experiments: productive test of form, productive test of meaning and receptive test of meaning. Testing multiple aspects of the knowledge of collocations and single words could provide a more accurate picture and more sensitive to even partial gains in knowledge (Webb, Newton \& Chang, 2013). For collocations, the productive test of form required the participants to provide the node words with the collocates given as the cues. For single words, the productive test of form required the participants to write down the words that they hear. The receptive and productive test of meaning for collocations and single words were translation tasks. An immediate posttest was administered right after the treatment and the delayed post-test was administered two weeks after the treatment.

\subsection{Procedure}

During the first session, the students had to learn and memorize the collocations and the single words on the learning material. They received the one-page learning material with English collocations and their Chinese meanings for the two experimental groups (20 collocations), and English single words and their Chinese meanings for the control group (20 single words). The treatment started with the teachers' brief instruction on the target items to verify that all items were clear whereby the teacher pronounced the items and explained the Chinese meaning of the items. The instruction lasted about 5 minutes. After the instruction, the students were given another 5 minutes with the instruction to memorize the target items. One minute before the end of the treatment, the students were informed that the learning materials would be collected after a minute to give them time for a final review. This would increase the ecological value of the present study since, in real learning scenarios, learners would always review the learning materials before the tests (e.g., Kronell, 2009).

Having completed the learning phase, the three groups of participants took the pen-and-pencil immediate post-test without notice. To avoid possible learning effect, the tests were ordered in a specific way: a productive test of form, a productive test of meaning and receptive test of meaning. Two weeks later, the unexpected delayed post-test was administered to the three groups.

\subsection{Scoring}

All post-tests adopted the dichotomy scoring, where the correct answer received one score and the incorrect answer received zero scores.

\section{Results}

\subsection{Treatment Group}

The Kolmogoroz-Smirnov test of normality showed that the data is normally distributed and parametric tests were used according. To determine whether there were overall differences between the experimental groups and control groups, a multivariate analysis of variance (MANOVA) was performed using the type of treatment (collocations with high MI score, collocations with low MI score and single words) and time of posttests (immediate and delayed) as the independent variables and scores of the posttests (productive test of form, productive test of meaning and receptive test of meaning) as the dependent measures. The MANOVA analysis showed significant overall difference for treatment group. It suggests that the type of treatment has significant effect on learning. The MANOVA analysis also showed significant overall difference for time of posttests. It suggests that the time of the posttest also has significance effect on learning. Besides the significant main effect of treatment groups and time of posttest, the interaction between treatment group and time of posttests were also identified. The simple main effect was tested on the two variables to examine where significance lay. The simple main effects analysis of time of tests showed that there are significant differences found between treatment at both immediate posttests and delayed posttests $(F(2,196)=18.81, p=.000$ at immediate posttest; $F(2,196)=$ $12.16, p=.000$ at delayed posttest). The simple main effect of treatment group showed that three treatment groups performed significant differently at two time intervals.

To understand the differences between the performance of three treatment groups at immediate posttest and delayed posttest respectively. The descriptive statistics are provided in Table 3. Two MANOVA were conducted with each at one time interval. The first MANOVA was conducted with three treatment group as the independent variable (high MI group, low MI group and single words group) and scores in three types of tests at the immediate posttest as the dependent variable (productive test of form, productive test of meaning and receptive test of meaning). The multivariate analysis showed that there was no significant difference between the three 
groups in the productive test of the form $(F(1,3)=1.51, p=.26$, partial $\eta 2=.03)$ and productive test of meaning $(F(1,3)=1.09, p=.34$, partial $\eta 2=.02)$. Since the differences did not achieve the significant level and the effect size was rather small, no post hoc analysis was conducted. This result suggested that the learning new items in collocations and single words produced similar gains in retention of the form of the words and collocations. The performance of the three treatment groups differs significantly in the receptive test of meaning $(F(1,3)=23.47, p=.00$, partial $\eta 2=.32)$.

Table 3. Mean and standard deviations of the scores of posttest

\begin{tabular}{ccccccc}
\hline & \multicolumn{3}{c}{ Immediate posttest } & \multicolumn{3}{c}{ Delayed posttest } \\
& $\mathrm{PF}$ & $\mathrm{PM}$ & $\mathrm{RM}$ & $\mathrm{PF}$ & $\mathrm{PM}$ & $\mathrm{RM}$ \\
\hline High MI & $9.51(5.08)$ & $9.33(4.94)$ & $18.09(2.45)$ & $6.87(3.95)$ & $6.17(4.36)$ & $12.2(3.64)$ \\
Low MI & $11.57(5.01)$ & $10.51(5.1)$ & $14.48(3.55)$ & $5.85(3.8)$ & $5.06(3.69)$ & $5.97(3.19)$ \\
Single words & $9.3(5.04)$ & $8.48(4.61)$ & $12.46(4.23)$ & $6.16(3.34)$ & $2.65(1.33)$ & $8.35(3.4)$ \\
\hline
\end{tabular}

Note: standard deviations are in brackets, Maximum score $=20 . P F=$ productive test of form; $P M=$ productive test of meaning; RM=receptive test of meaning.

A post hoc LSD test was done to find out where the significance lay between the groups (Table 4). The paired comparison indicated significant differences lay between the mean test scores of High MI group and low MI group, high MI group and single words group and low MI group and single words group. The results suggest that learning new items in collocations led to better learning gain in the receptive meaning of the items. And, learning collocations with High MI scores were more effective in retention of the meaning than learning collocations with low MI scores.

The second MANOVA analysis was conducted to examine whether there were significant differences between treatment groups on the three posttests in the delayed posttest. The MANOVA was conducted with the treatment group as the independent measures and scores of the three types of posttest as the dependent measures. The multivariate tests showed that there were significant differences between the performance of the treatment groups on the delayed post-tests. The three treatment groups performed comparatively in the productive test of form with no significant difference between the groups $(F(1,3)=0.615, p=.54$, partial $\eta 2=0.013)$. The performance on the remaining two tests showed significant differences between three treatment groups $(F(1,3)=$ $8.7, p=.000$, partial $\eta 2=0.161$ for productive test of meaning; $F(1,3)=26.56, p=.000$, partial $\eta 2=0.369$ for receptive test of meaning). The results showed that, like immediate posttest, different learning conditions led to similar learning outcomes in terms of the retention of the form of target items. Although the high MI group performed better than the low MI group on this test, the results did not achieve significance level.

The post hoc LSD analysis was conducted on the two tests of a productive test of meaning and receptive test of meaning (Table 5). In the productive test of meaning, the high MI group performed slightly better than the low MI group, although the differences did not achieve a significant level. Both high MI group and low MI group had high mean test scores than the single words group. In the receptive test of meaning, high MI group outperform the other two groups significantly.

Table 4. Post hoc LSD analysis of between-group variance of immediate posttest

\begin{tabular}{lllll}
\hline & & High MI group & low MI group & single words group \\
\hline \multirow{2}{*}{ RM } & High MI group & & $3.58^{* *}$ & $5.71^{* *}$ \\
& Low MI group & & $2.13^{*}$
\end{tabular}

Note: Mean difference followed by significance value in brackets. $\mathrm{RM}=$ receptive test of meaning. ${ }^{*} p<.05,{ }^{* *} p$ $<.001$. 
Table 5. Post hoc LSD analysis of between-group variance of delayed posttest

\begin{tabular}{|c|c|c|c|c|c|}
\hline & & high MI group & low MI group & $\begin{array}{l}\text { single } \\
\text { group }\end{array}$ & words \\
\hline \multirow{2}{*}{$\mathbf{P F}$} & high MI group & & 1.02 & 0.71 & \\
\hline & Low MI group & & & -0.32 & \\
\hline \multirow{2}{*}{ PM } & high MI group & & 1.12 & $3.52 *$ & \\
\hline & Low MI group & & & $2.42 *$ & \\
\hline \multirow{2}{*}{$\mathbf{R M}$} & high MI group & & $6.23 *$ & $3.84 *$ & \\
\hline & Low MI group & & & $-2.39 *$ & \\
\hline
\end{tabular}

Note: Mean difference followed by significance value in brackets. $\mathrm{PF}=$ productive test of form; $\mathrm{PM}=$ productive test of meaning; $\mathrm{RM}=$ receptive test of meaning. ${ }^{*} p<.01$.

The results showed that advantage of learning new items in collocations over single words on productive test of meaning and receptive test of meaning. However, there were no significant differences in learning outcomes in the productive test of form. In addition, the results suggest that learning new items in collocations with high MI scores collocates could lead to significant better learning outcomes in the three types of posttests of vocabulary knowledge of form and meaning. The learning gain was more prominent in the receptive and productive knowledge of meaning than on the productive knowledge of form.

\subsection{Collocate-node Relationship}

The number and percentage of correct answers for each posttest is listed in Table 6. A close look at the number of correct answers for each type of collocations shows that, in most of the cases, there were more correct answers for the adjective-noun collocations that the verb-noun collocations. It seems that learners could remember more adjective-noun collocations after the treatments. However, in the treatment of low MI group, the correct answers for the verb-noun collocations were consistently more than the adjective-noun collocations, which means that, in this treatment, the verb-noun collocations led to the better recall and retention rates. This suggests that the learning burden of the types of collocations are under the influence of other variables, like the treatment that learners received for vocabulary learning. It needs further parametric analysis to establish the influence of variables, and see if there exists any interaction between the variables on the learning outcome.

MANOVA was performed with the treatment (high MI group, low MI group, single words) and type of collocate-node relationship (verb-noun and adjective-noun) as the independent variable and the test scores as the dependent variable. The MANOVA test showed that there were significant differences between types of collocations and between groups. There was no significant interaction between the type of the collocation-node relationship and treatment groups. The results showed that the effects of collocation-node relationship on the learning outcomes may be under the influence of other variables like the treatment groups, however, this effect did not achieve a significant level in the analysis.

Since we are interested in the differences between the type of collocate-node relationship, a pairwise comparison was conducted to find out which type of collocation-node relationship led to between recall and retention of target items. The results of $t$-test showed that the test scores of the two types of collocations differ significantly both in the immediate and delayed posttest. Verb-noun collocations had significantly lower test scores than the adjective-noun collocations at two time intervals $(t=-5.290, \mathrm{df}=305, p=.000, d=.43$ for immediate posttest; $t$ $=-2.131, \mathrm{df}=277, p=.03, d=.18$ for delayed posttest). The learning difficulty of verb-noun collocations was much less salient after two weeks of the intervention. 
Table 6. The number and the percentage of correct answer of each type of posttest in the posttest

\begin{tabular}{ccccc}
\hline Immediate posttest & & PF & PM & RM \\
\hline high MI group & $\mathrm{VN}$ & $146(42.9 \%)$ & $138(40.2)$ & $276(81.2 \%)$ \\
& $\mathrm{AdjN}$ & $168(49.4 \%)$ & $170(50 \%)$ & $321(94.4 \%)$ \\
low MI group & $\mathrm{VN}$ & $204(60 \%)$ & $183(53.8 \%)$ & $251(73.8 \%)$ \\
& $\mathrm{AdjN}$ & $191(56.2 \%)$ & $175(51.2 \%)$ & $257(75.6 \%)$ \\
single words group & $\mathrm{VN}$ & $144(43.6 \%)$ & $123(37.2 \%)$ & $177(53.6 \%)$ \\
& $\mathrm{AdjN}$ & $176(53.3 \%)$ & $166(50.3 \%)$ & $244(73.9 \%)$ \\
\hline Delayed posttest & & $\mathrm{PF}$ & $\mathrm{PM}$ & $\mathrm{RM}$ \\
\hline high MI group & $\mathrm{VN}$ & $98(32.6 \%)$ & $89(29.7 \%)$ & $157(52.3 \%)$ \\
& $\mathrm{AdjN}$ & $108(36 \%)$ & $96(32.2 \%)$ & $189(63 \%)$ \\
low MI group & $\mathrm{VN}$ & $110(33.3 \%)$ & $90(27.3 \%)$ & $104(31.2 \%)$ \\
& $\mathrm{AdjN}$ & $83(25.2 \%)$ & $77(23.3 \%)$ & $93(28.2 \%)$ \\
single words group & $\mathrm{VN}$ & $84(27.1 \%)$ & $41(13.2 \%)$ & $96(30.9 \%)$ \\
& $\mathrm{AdjN}$ & $107(34.5 \%)$ & $41(13.2 \%)$ & $163(52.9 \%)$ \\
\hline
\end{tabular}

Notes: the number of correct answers are presented with the percentage in the brackets. VN=verb-noun collocation, AdjN=adjective-noun collocations. $\mathrm{PF}=$ productive test of form; $\mathrm{PM}=$ productive test of meaning; $\mathrm{RM}=$ receptive test of meaning.

\section{General Discussion}

In answer to the first research question, the study indicated that learning new items in collocations yielded better retention and retrieval of the form and meaning than learning new items in single words. However, this advantage is not as pronounced as in Kasahara (2011). The present study differs from Kasahara's study in an important aspect. In his study, the learning gain was measured with one test of vocabulary knowledge: the receptive test of meaning whereas the present study has used three tests of vocabulary knowledge to examine the learning gains in two aspects of form and meaning. The two experimental groups also showed clear advantage over control group in the receptive test of meaning in the present study. Taking the results of two studies together, it seems that learning new items in collocations lead to better retention of the meaning of target items, but not on the form.

There are three possible reasons that could explain the better retention rate in the experimental group. The first reason is the facilitative effect of collocates plays as cues for integrating the new word into the mental lexicon. In the process of new word learning, the known words being used as the collocate of the new words have created a cue for storing and retrieval of the meaning of the new items. The cues could speed up the initial process of incorporating a new L2 item into the mental lexicon through strengthening the link of L2 form and L1 meaning (Jiang, 2000). The cue that the collocates have created for the target items were more resilient facing the attrition of the word knowledge, especially in the case of the productive knowledge of meaning. In the delayed posttest, the participants in the experimental group could score correctly more than twice as much as the correct answers of the participants in the control group.

The second reason for the better scores for the experimental group is the innate quality of the collocations, i.e, congruency of the L1 and L2 collocations. The collocations in the experiment could be classified as the congruent collocations, which implies that there are identical lexical choices in L1 and L2. The collocations in the present study could find equivalent translation in Chinese. For example, bestselling memoir could be directly translated as 畅销的回忆录; fruity aroma could be translated as 水果的香气. Wolter and Gyllstad (2011) commented on this facilitative effect of collocational learning more clearly in their observation that "When an L2 word is activated, it stimulates not only the L2 words (known) L2 collocations, but also the L1 translation equivalent and that word's L1 collocations" (p.444).

The third reason for the advantage of the collocational learning could be the evidence for learners being able to store collocations holistically in the mental lexicon, and therefore, when they were asked to retrieve in the posttest, they showed better performance in terms of greater accuracy in the form and meaning of the target items. Past studies on non-native speakers showed that learners could store collocations as a holistic unit in the 
mental lexicon ((e.g., Jiang \& Nekrasova, 2007; Siyanova-Chanturia, Conklin \& Schmitt, 2011). In the present study, the learners in the experimental group could retrieve the meanings (receptive task) with greater accuracy than the learners in the control group. This shows that, in the early stage of new item learning, advanced learners could see the collocations as holistic units. Knowing one part of the combinations primes the knowledge of the remaining components. However, when we consider the vast body of research into learner writing, we have concerns about the extent to which learners could holistically store the collocations in their mental lexicon (Durrant \& Schmitt, 2009). It seems likely that, when learners first encountered collocations without context, they could memorize them as a holistic unit. However, if learners were not allowed to access the items productively, the holistic storage of the collocations would regress back to storing the collocations as separate components only subject to the grammaticalness when used.

The second research question examined whether collocations with greater association strength would lead to better retention than collocations with fewer association strength. The results suggest that collocations with strong association strength could lead to stronger retention during both immediate and delayed posttest. The differences in performance between the two experimental groups were more pronounced in the delayed posttest than in the immediate posttest. Although the memorization before test would increase the ecological value of the study as explained in the previous section, the effect of the different treatments could very likely be offset by the memorization. Considering this, the discussion would primarily be on the results of the delayed posttest for research question two. The reason behind the better retention of the collocations with higher mutual information value is that they are more likely to be processed holistically rather than being treated as two different words and processed independently. Ellis, Simpson-Vlach \& Maynard (2008) commented in their paper that "their processing is a psycholinguistic instantiation of the idiom principle in that they (native speakers) preferentially recognize high-MI formulas as units." (p.301). Although in their study, the advanced ESL learners were sensitive to frequency information but not to the mutual information of the formulaic sequences, the present study shows that learners show better retention of the collocations with higher MI values during new item learning. In the present study, collocations with high MI score like bestselling memoir, fruity aroma include adjectives that are more exclusively used with the nouns than in the cases of the collocations with low MI scores like new memoir, strong aroma, recent slump and huge metropolis. In the posttest of the knowledge of form, when the participants saw the collocate bestselling as the prompt, they were more likely to remember memoir than the prompt new. The same goes for the posttest of the knowledge of meaning. This shows that the participants were more likely to remember the meaning of the high MI collocations in posttests and produce the proper translations.

The third research question were on the learning load of the collocate-node relationship. In most of the posttests, the learners could score better on the adjective-noun collocations, except in the test outcomes of the low MI group. This result is in line with Liao and Fukuya (2004) and Peters (2015)'s findings which also showed that the chances that adjective-noun collocations would lead to better retention was also influenced by the type of test. The learning difficulty of verb-noun collocations lies in the way of presentation in the learning materials. Morphological variation of the verb forms is one of the major reasons that give rise to the learning difficulties of the verb-noun collocations (Laufer, 2011). Learners need to process the different verb forms in the sample sentences and the inserted adjective strong. In the present study, the target collocations were presented in paired-associate learning format, which only involved one form without variation. Therefore, in the instruction, learners did not come across different morphological variations which could leave them disoriented. This finding suggests that, at the early stage of new verb-noun collocational learning, it is better to present one single verb form to create a unified picture in learners' memory and long-term retention.

\section{Pedagogical Implications}

The present study has two important pedagogical implications. The first pedagogical implication is the use of collocations when presenting new words for learning. Teachers may direct learners' attentional resources explicitly to the form of the collocates to raise learners' awareness, and hence, enhance the effectiveness of instruction on more aspects of vocabulary knowledge. It could be realized by making the target collocations salient to learners using visual enhancements like underlining the collocations and collocations in bold or italics. (Boers, Eyckmans \& Lindstromberg, 2014).

To further build upon the first implication is the type of collocations that should be included in the instruction. During the selection of collocations for teaching based on the corpus information, teachers for the advanced learners might shift their focus from high frequency collocations to collocations with lower frequency but higher association strength. Drawing their attention to these collocations might be the tentative move to improve the use of low frequency collocations in written and spoken production and reduce learners' dependence on high frequency collocations in writing (Wang, 2019). 


\section{Conclusions}

The results support the advantage of teaching new vocabulary items in collocations over single words. It corroborates the findings in the psycholinguistic research to show the facilitative effect of collocations in the retention of meaning, and at the same time, supports the assumption that advanced EFL learners could store newly learnt collocations as holistic units in their mental lexicon. Additionally, the present study indicates that collocations with greater associate strength could lead to better short-term and long-term retention of the productive and receptive knowledge of meaning. The interlexcial factor (collocation-node relationship) showed significant influence on the learning outcomes in the present study, however, this influence was not so pronounced compared to previous study (Peters, 2015) and the effect was minimal in the delayed posttest. The result of the present study is an encouraging piece of news which suggest that the presentation of verb-noun collocations in paired-associate format during instruction could lead to comparable retention as the adjective-noun collocations.

\section{References}

Bestgen, Y., \& Granger, S. (2014). Quantifying the development of phraseological competence in L2 English writing: An automated approach. Journal of Second Language Writing, 26, $28-41$. https://doi.org/10.1016/j.jslw.2014.09.004

Boers, F., \& Lindstromberg, S. (2012). Experimental and Intervention Studies on Formulaic Sequences in a Second Language. Annual Review of Applied Linguistics, 32, 83-110. https://doi.org/10.1017/S0267190512000050

Boers, F., Demecheleer, M., Coxhead, A., \& Webb, S. (2014). Gauging the effects of exercises on verb-noun collocations. Language Teaching Research, 18(1), 54-74. https://doi.org/10.1177/1362168813505389

Boers, F., Eyckmans, J., \& Lindstromberg, S. (2014). The effect of a discrimination task on L2 learners' recall of collocations and compounds. International Journal of Applied Linguistics (United Kingdom), 24(3), 357-369. https://doi.org/10.1111/ijal.12033

Conklin, K., \& Schmitt, N. 2007. Formulaic sequences: Are they processed more quickly than nonformulaic language by native and nonnative speakers? Applied Linguistics, 29(1), 72-89. https://doi.org/10.1093/applin/amm022

Durrant, P. (2014). Corpus frequency and second language learners' knowledge of collocations: A meta-analysis. International Journal of Corpus Linguistics, 19(4), 443-477. https://doi.org/10.1075/ijcl.19.4.01dur

Durrant, P., \& Schmitt, N. (2009). To what extent do native and non-native writers make use of collocations? IRAL - International Review of Applied Linguistics in Language Teaching, 47(2), 157-177. https://doi.org/10.1515/iral.2009.007

Eyckmans, J., Boers, F., \& Lindstromberg, S. (2016). The impact of imposing processing strategies on L2 learners' deliberate study of lexical phrases. System, 56, 127-139. https://doi.org/10.1016/j.system.2015.12.001

Ellis, N. C., Simpson-Vlach, R., \& Maynard, C. (2008). Formulaic Language in Native and Second Language Speakers: Psycholinguistics, Corpus Linguistics, and TESOL. TESOL Quarterly, 42(3), 375-396. https://doi.org/10.1002/j.1545-7249.2008.tb00137.x

Fernancez, B., \& Schmitt, N. (2015). How much collocation knowledge do L2 learners have? The effects of frequency and amount of exposure. ITL-International Journal of Applied Linguistics, 166(1), 94-126. https://doi.org/10.1075/itl.166.1.03fer

Foster, P. (2001). Rules and routines: a consideration of their role in the task-based language production of native and non-native speakers. In M. Bygate, P. Skehan, \& M. Swain (Eds.), Language tasks: teaching, learning and testing(pp.79-94). London: Longman.

Granger, S., \& Bestgen, Y. (2014). The use of collocations by intermediate vs. advanced non-native writers: A bigram-based study. IRAL - International Review of Applied Linguistics in Language Teaching, 52(3), 229-252. https://doi.org/10.1515/iral-2014-0011

Gyllstad, H., \& Wolter, B. (2016). Collocational processing in light of the phraseological continuum model: Does semantic transparency matter? Language Learning, 66(2), 296-323. https://doi.org/10.1111/lang.12143 
Hsu, J.-Y., \& Chiu, C.-Y. (2008). Lexical collocations and their relation to speaking proficiency of college EFL learners in Taiwan. Asian EFL Journal, 10, 181-204.

Jiang, N. (2000). Lexical representation and development in a second language. Applied Linguistics, 21(1), 47-77. https://doi.org/10.1093/applin/21.1.47

Jiang, N., \& Nekrasova, T. M. (2007). The processing of formulaic sequences by second language speakers. Modern Language Journal, 91(3), 433-445. https://doi.org/10.1111/j.1540-4781.2007.00589.x

Kasahara, K. (2011). The effect of known-and-unknown word combinations on intentional vocabulary learning. System, 39(4), 491-499. https://doi.org/10.1016/j.system.2011.10.001

Laufer, B. (2011). The contribution of dictionary use to the production and retention of collocations in a second language. International Journal of Lexicography, 24(1), 29-49.https://doi.org/10.1093/ijl/ecq039

Laufer, B., \& Girsai, N. (2008). Form-focused instruction in second language vocabulary learning: A case for contrastive analysis and translation. Applied Linguistics, 29(4), 694-716.https://doi.org/10.1093/applin/amn018

Liao, Y. \&. Fukuya, Y. J. (2004). Avoidance of phrasal verbs: The case of Chinese learners of English. Language Learning, 193-226. https://doi.org/10.1111/j.1467-9922.2004.00254.x

Martinez, R., \& Murphy, V. A. (2011). Effect of Frequency and Idiomaticity on Second Language Reading Comprehension. Source: TESOL Quarterly, 45(2), 267-290. https://doi.org/10.5054/tq.2011.247708

Nakata, T., \& Webb, S. (2015). Does studying vocabulary in smaller sets increase learning? Studies in Second Language Acquisition, 1-30.

Pellicer-Sanchez, A. (2015). Learning L2 collocations incidentally from reading. Language Teaching Research, 1-22. https://doi.org/10.1177/1362168815618428

Peters, E. (2012). The differential effects of two vocabulary instruction methods on EFL word learning: A study into task effectiveness. IRAL - International Review of Applied Linguistics in Language Teaching, 50(3), 213-238. https://doi.org/10.1515/iral-2012-0009

Peters, E. (2014). The effects of repetition and time of post-test administration on EFL learners' form recall of single words and collocations. Language Teaching Research, 18(1), 75-94. https://doi.org/10.1177/1362168813505384

Peters, E. (2015). The learning burden of collocations: The role of interlexical and intralexical factors. Language Teaching Research, 19, 1-26. https://doi.org/10.1177/1362168814568131

Schmitt, N. (2010). Researching Vocabulary: A Vocabulary Research Manual. Palgrave Press.https://doi.org/10.1057/9780230293977

Schmitt, N., Schmitt, D., \& Clapham, C. (2001). Developing and exploring the behaviour of two new versions of the Vocabulary Levels Test. Language Testing, 18(1), 55-88. https://doi.org/10.1177/026553220101800103

Siyanova-Chanturia, a., Conklin, K., \& Schmitt, N. (2011). Adding more fuel to the fire: An eye-tracking study of idiom processing by native and non-native speakers. Second Language Research, 27(2), 251-272. https://doi.org/10.1177/0267658310382068

Stengers, H., Boers, F., Housen, A., \& Eyckmans, J. (2010). Does "chunking" foster chunk-uptake? In S. De Knop, F. Boers, \& A. De Rycker (Eds.), Fostering Language Teaching Difficiency Through Cognitive Linguistics (pp. 99-117). Berlin, Germany: Mouton de Gruyter.https://doi.org/10.1515/9783110245837.99

Szudarski, P. (2012). Effects of meaning- and formed-focused instruction on the acquisition of verb-noun collocations in L2 English. Journal of Second Language Teaching and Research, 1, 3-37.

Wang, C. (2019). Profiling collocations in EFL writing of Chinese tertiary learners. RELC Journal, 50(1), 53-70. https://doi.org/10.1177/0033688217716507

Webb, S., Newton, J., \& Chang, A. (2013). Incidental learning of collocation. Language Learning, 63(1), 91-120. https://doi.org/10.1111/j.1467-9922.2012.00729.x

Wolter, B., \& Gyllstad, H. (2011). Collocational Links in the L2 Mental Lexicon and the Influence of L1 Intralexical Knowledge. Applied Linguistics, 32(4), 430-449. https://doi.org/10.1093/applin/amr011

Wolter, B., \& Gyllstad, H. (2013). Frequency of input and L2 collocational processing. Studies in Second Language Acquisition, 35(3), 451-482.https://doi.org/10.1017/S0272263113000107 
Appendix List of the 20 high MI score collocation, 20 low MI score collocations and single words

\begin{tabular}{|c|c|c|c|c|c|c|c|c|c|}
\hline \multicolumn{4}{|c|}{ collocations with high MI score } & \multicolumn{4}{|c|}{ collocations with low MI score } & \multicolumn{2}{|c|}{ single words } \\
\hline verb-noun & $\begin{array}{c}\text { MI } \\
\text { score }\end{array}$ & adjective-noun & $\begin{array}{c}\text { MI } \\
\text { score }\end{array}$ & verb-noun & $\begin{array}{c}\text { MI } \\
\text { score }\end{array}$ & adjective-noun & $\begin{array}{c}\text { MI } \\
\text { score }\end{array}$ & verb & noun \\
\hline $\begin{array}{c}\text { roam } \\
\text { streets }\end{array}$ & 6.59 & $\begin{array}{c}\text { bestselling } \\
\text { memoir }\end{array}$ & 8.39 & roam land & 3.16 & new memoir & 3.05 & roam & memoir \\
\hline $\begin{array}{c}\text { unleash } \\
\text { creativity }\end{array}$ & 6.45 & hearty chuckle & 7.15 & $\begin{array}{l}\text { unleash } \\
\text { energy }\end{array}$ & 3.36 & low chuckle & 3.83 & unleash & chuckle \\
\hline $\begin{array}{c}\text { reconcile } \\
\text { differences }\end{array}$ & 5.56 & $\begin{array}{l}\text { long-running } \\
\text { sitcom }\end{array}$ & 9.28 & $\begin{array}{l}\text { reconcile } \\
\text { value }\end{array}$ & 3.34 & funny sitcom & 3.83 & reconcile & sitcom \\
\hline $\begin{array}{c}\text { curtail } \\
\text { spending }\end{array}$ & 5.26 & fruity aroma & 9.29 & $\begin{array}{c}\text { curtail } \\
\text { cost }\end{array}$ & 3.58 & strong aroma & 3.2 & curtail & aroma \\
\hline $\begin{array}{c}\text { harness } \\
\text { energy }\end{array}$ & 6.71 & holy relics & 6.39 & $\begin{array}{l}\text { harness } \\
\text { resources }\end{array}$ & 3.49 & religious relics & 3.16 & harness & relics \\
\hline $\begin{array}{l}\text { soothe } \\
\text { fear }\end{array}$ & 6.06 & $\begin{array}{c}\text { sunny } \\
\text { disposition }\end{array}$ & 7.92 & $\begin{array}{l}\text { soothe } \\
\text { spirit }\end{array}$ & 3.91 & $\begin{array}{c}\text { natural } \\
\text { disposition }\end{array}$ & 3.12 & soothe & disposition \\
\hline tame beast & 7.32 & $\begin{array}{l}\text { economic } \\
\text { slump }\end{array}$ & 5.41 & tame hair & 3.25 & recent slump & 3.12 & tame & slump \\
\hline $\begin{array}{l}\text { transcend } \\
\text { boundary }\end{array}$ & 8.34 & $\begin{array}{c}\text { worthwhile } \\
\text { endeavor }\end{array}$ & 7.17 & $\begin{array}{l}\text { transcend } \\
\text { culture }\end{array}$ & 3.08 & $\begin{array}{l}\text { successful } \\
\text { endeavor }\end{array}$ & 3.02 & transcend & endeavor \\
\hline $\begin{array}{c}\text { divert } \\
\text { attention }\end{array}$ & 7.35 & emotional toll & 5.26 & $\begin{array}{l}\text { divert } \\
\text { money }\end{array}$ & 3.57 & tragic toll & 3.63 & divert & toll \\
\hline $\begin{array}{c}\text { erode } \\
\text { confidence }\end{array}$ & 5.96 & $\begin{array}{c}\text { modern } \\
\text { metropolis }\end{array}$ & 5.32 & $\begin{array}{l}\text { erode } \\
\text { power }\end{array}$ & 3.15 & $\begin{array}{c}\text { huge } \\
\text { metropolis }\end{array}$ & 3.19 & erode & metropolis \\
\hline
\end{tabular}

\section{Copyrights}

Copyright for this article is retained by the author(s), with first publication rights granted to the journal.

This is an open-access article distributed under the terms and conditions of the Creative Commons Attribution license (http://creativecommons.org/licenses/by/4.0/). 